\title{
Influence of Additives of Carbon Nanotubes and Oxide Nanofibers on Mechanical Properties of Aluminum Composite
}

\author{
Artem V. Alekseev*a,b, \\ Maxim A. Esikov', Vyacheslav I. Malic, \\ Alexander A. Khassin ${ }^{\mathrm{b}}$, Michael R. Predtechenskiy ${ }^{\mathrm{a}}$ \\ ${ }^{a} S . S$. Kutateladze Institute of Thermophysics $S B R A S$ \\ 1 Academician Lavrentiev, Novosibirsk, 630090, Russia \\ ${ }^{b}$ International Science Centre of Thermophysics and Energetics \\ 7/11 Kutateladze Str., Novosibirsk, 630128, Russia \\ 'Institute of Hydrodynamics SB RAS \\ 15 Academician Lavrentiev, Novosibirsk, 630090, Russia
}

Received 03.08.2018, received in revised form 12.10.2018, accepted 04.01.2019

Composite material with aluminum matrix reinforced by carbon nanotubes (CNT) and oxide nanofibers (NF) was made by powder metallurgy method. Powder mixtures were made by low energy milling on drum ball mill. Composite samples were manufactured by spark plasma sintering system. Microstructure analysis showed agglomeration of CNT and NF in composite materials. Correlation between flexural strength and unit mass of composites was revealed. Nevertheless, the use of low energy milling allows minimizing the damage of carbon nanotubes and oxide nanofibers during the preparation of mixtures. From this point of view it is suitable for making composites with high elastic modulus. It was shown that addition of 5-12\% wt of CNT can increase flexural modulus by 30-189\%. Also was shown that addition of 5\%wt of oxide nanofibers increase flexural modulus by $78 \%$.

Keywords: carbon nanotubes, oxide nanofibers, composite material, spark plasma sintering, flexural module.

Citation: Alekseev A.V., Esikov M.A., Mali V.I., Khassin A.A., Predtechenskiy M.R. Influence of additives of carbon nanotubes and oxide nanofibers on mechanical properties of aluminum composite, J. Sib. Fed. Univ. Eng. technol., 2019, 12(4), 416-426. DOI: $10.17516 / 1999-494$ X-0146.

(C) Siberian Federal University. All rights reserved

This work is licensed under a Creative Commons Attribution-NonCommercial 4.0 International License (CC BY-NC 4.0).

* Corresponding author E-mail address: artem.alekseev@ocsial.com 


\title{
Влияние добавок углеродных нанотрубок
}

\section{и оксидных нановолокон на механические свойства композита на основе алюминия}

\author{
А.В. Алексеев ${ }^{\mathrm{a}, \boldsymbol{0}}$, М.А. Есиков ${ }^{\mathrm{B}}$, \\ В.И. Мали ${ }^{\text {, }, ~ А . А . ~ Х а с и н ~}{ }^{\sigma}$, М.Р. Предтеченский ${ }^{\mathrm{a}}$ \\ ${ }^{a}$ Институт теплофизики им. С.С. Кутателадзе СО РАН \\ Россия, 630090, Новосибирск, пр. Академика Лаврентьева, 1 \\ ${ }^{6}$ Международный научный иентр по теплофизике и энергетике \\ Россия, 630128, Новосибирск, ул. Кутателадзе, 7/11 \\ ${ }^{6}$ Институт гидродинамики им. М.А. Лаврентьева СО РАН \\ Россия, 630090, Новосибирск, пр. Академика Лаврентьева, 15
}

С помощью метода порошковой металлургии получен композитный материал на основе алюминиевой матрицы, упрочненной добавками углеродных нанотрубок (УНТ) и оксидных нановолокон (НВ). Для изготовления порошковых смесей использовали низкоэнергетический помол на шаровой барабанной мельнице. Образиы композитного материала получали на установке электроискрового спекания. Анализ микроструктуры композитов показал присутствие в них агломератов нанотрубок и нановолокон. Обнаружена корреляция между плотностью и прочностью на изгиб композитных материалов. Тем не менее, использование низкоэнергетического помола позволяет минимизировать повреждение УНТ и НВ в ходе приготовления смесей и с этой точки зрения предпочтительно для получения композитов с высоким модулем упругости. Показано, что добавки углеродных нанотрубок в количестве 5-12\% масс. позволяют увеличить модуль упругости композитов на изгиб на 30-189\%, а добавки оксидных нановолокон в количестве $5 \%$ масс. - на $78 \%$.

Ключевые слова: углеродные нанотрубки, оксидные нановолокна, композитный материал, электроискровое спекание, модуль упругости при изгибе.

\section{Введение}

В последние годы большое внимание уделяется исследованиям в области получения металломатричных композитов, упрочненных углеродными нанотрубками (УНТ). Показано, что небольшие добавки УНТ позволяют значительно улучшить механические свойства алюминия и его сплавов [1].

Композиты на основе алюминия, упрочненные углеродными нанотрубками, в большинстве работ изготавливают методами порошковой металлургии. При этом наиболее часто для изготовления компактов используют горячее прессование или электроискровое спекание (SPS); эти методы имеют преимущество перед простым спеканием, поскольку позволяют получать большую плотность материала за счет того, что процесс высокотемпературного спекания ведется с приложением внешнего давления. Метод SPS отличается тем, что с помощью него можно получить лучшее сцепление между частицами благодаря разрушению оксидной пленки в момент протекания тока через границы частиц металла [2].

Для получения композитов методом SPS предварительно готовят смеси углеродных нанотрубок с порошком алюминия, используют шаровые планетарные мельницы [3-5], а также 
низкоэнергетический помол на барабанных мельницах [2]. Процесс изготовления смесей в некоторых работах проводят с применением добавок, препятствующих слипанию частиц порошка, таких как спирт [6] или стеариновая кислота [5]. Для удаления этих добавок из смеси после проведения помола проводят дополнительную стадию отжига в вакууме или токе инертного газа.

Встречаются работы, в которых реализованы другие методы получения смесей. Так, в работе [7] на УНТ наносили медь с помощью метода молекулярного смешения, после чего смешивали с порошком алюминия. А в работе [8] порошки смешивали в растворе резины в бензине, после чего резину выпаривали для получения готовой смеси. В работе [9] мелкий порошок алюминия с размером частиц 6 мкм смешивали с УНТ с помощью ультразвука в среде спирта, затем смесь сушили для удаления растворителя.

Компактирование порошковых смесей с помощью SPS проводят в вакууме при температурах 480-630 ${ }^{\circ} \mathrm{C}[6,8]$. При этом, как показано в работе [5], в процессе электроискрового спекания эффективное разрушение оксидной пленки на частицах алюминиевого порошка и хороший контакт между частицами получаются, если спекание проводится выше некоторой критической температуры, которая для порошка алюминия с размером частиц 20-100 мкм лежит в области $430{ }^{\circ} \mathrm{C}$, а для композитного порошка, содержащего $1 \%$ УНТ, эта температура находится в районе $530{ }^{\circ} \mathrm{C}$.

Согласно данным разных работ, для эффективного прессования алюминиевых композитов методом SPS достаточно давления 30-50 МПа [6, 7, 9], при этом время прессования составляет 5-30 мин [2, 4, 6, 7].

Методом SPS изготавливают алюминиевые композиты с содержанием УНТ 0,1-4 \% масс. $[2,3,4,7,9]$ при этом получают увеличение предела прочности при растяжении до $80 \%$, предела текучести до 241 \% и микротвердости до 158 \%.

В подавляющем большинстве исследований уделяется внимание именно механическим свойствам композитов при растяжении, в то время как прочностным свойствам при изгибе посвящено небольшое количество работ. При этом композитные материалы получают горячим прессованием или холодным прессованием и спеканием.

В работе [10] материал изготавливали с помощью холодного прессования под давлением 550 МПа и спекания в вакууме при температуре $620{ }^{\circ} \mathrm{C}$. За счет добавки $1,5 \%$ масс. многостенных углеродных нанотрубок (МУНТ) получили увеличение прочности на изгиб на 42 \% и модуля упругости на изгиб на 73 \% (модуль упругости композита составил 450 МПа). В работе [11] алюминиевый сплав А6061 упрочнили с помощью 1 \% масс. МУНТ и добились увеличения прочности на изгиб на 7-25\%. Авторы отметили, что с увеличением времени помола порошковой смеси, из которой готовят композит, качество распределения УНТ в алюминии улучшается, но длина самих МУНТ становится меньше. В другой работе для изготовления алюминия с содержанием $1 \%$ об МУНТ [12] использовали горячее прессование порошковой смеси при температуре $550{ }^{\circ} \mathrm{C}$ и давлении 570 МПа. Помол смеси проводили в аргоне с последующей пассивацией, за счет выдержки порошка в боксе с контролируемой атмосферой, и перед горячим прессованием форму с порошком вакуумировали 1,5 часа. В результате получили увеличение предела текучести при изгибе на 350 \%. В другой работе [13] показали, что диаметр используемых УНТ значительно влияяет на прочность алюминия. Авторы сравнили три типа УНТ с 
диаметрами в диапазонах менее 8, 10-20 и 30-50 нм. Лучшее упрочнение получили при использовании нанотрубок с диаметром 10-20 нм: увеличение прочности на изгиб составило $112 \%$, что почти в 2 раза больше, чем для УНТ меньшего и большего диаметров. Композит они также получали с помощью холодного прессования и спекания.

В работе [14] смесь МУНТ и алюминиевого порошка получали смешиванием порошков в ацетоне с последующей просушкой смеси и горячим прессованием при температуре $200{ }^{\circ} \mathrm{C}$ и давлении 0,6 МПа. Затем отпрессованные брикеты плавили в индукционной печи и разливали на машине центробежного литья. За счет добавки 0,5-1 \% масс. МУНТ они получили увеличение модуля упругости на изгиб на 6-8 \%.

Следует отметить, что в подавляющем большинстве статей для получения металломатричных композитов используются МУНТ. В доступной литературе практически нет работ по исследованию механических свойств при изгибе алюминиевых композитов, армированных одностенными углеродными нанотрубками (ОУНТ) или нановолокнами оксида алюминия. В нашей работе проведено исследование влияния добавок ОУНТ и нановолокон оксида алюминия на механические свойства алюминиевых композитов при изгибе.

\section{Описание экспериментов}

Для изготовления композитного материала использовали порошок алюминия (чистотой 99,3 \% масс., производства ООО СУАЛ ПМ) с размером частиц 63 мкм и одностенные углеродные нанотрубки с диаметром 1-2 нм и длиной более 5 мкм производства OCSiAl, а также нановолокна оксида алюминия диаметром 8-15 нм и длиной более 1 мкм, синтезированные в нашей лаборатории. Снимки ПЭМ оксидных нановолокон и ОУНТ приведены на рис. 1 и 2.

Композиты, армированные ОУТН и оксидными нановолокнами, изготавливали методом порошковой металлургии, который заключался в приготовлении смеси порошков металла и упрочняющей фазы на шаровой барабанной мельнице, с последующим компактированием порошковой смеси на установке SPS (LABOX 1575 Sinterland, Japan). Режимы получения смесей и спекания брикетов приведены в табл. 1.

Испытание на изгиб проводили на сервогидравлической испытательной машине BISS UTN-100kN на образцах с квадратным сечением со стороной 5 мм и длиной 16 мм. Испытания на твердость по Бринеллю выполняли с использованием твердомера ИТБРВ187,5-А на
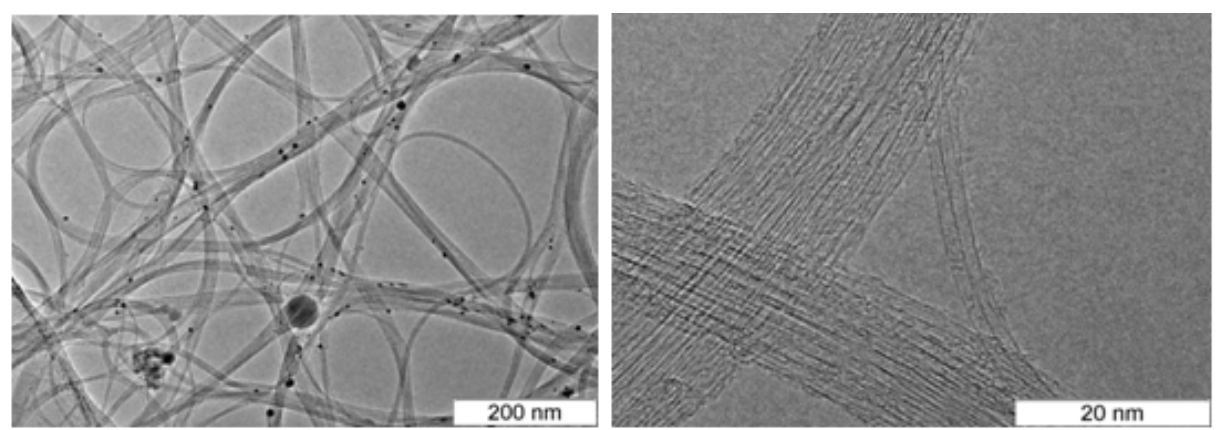

Рис. 1. Микрографии ОУНТ

Fig. 1. Electron micrographs of SWCNT

$$
-419-
$$



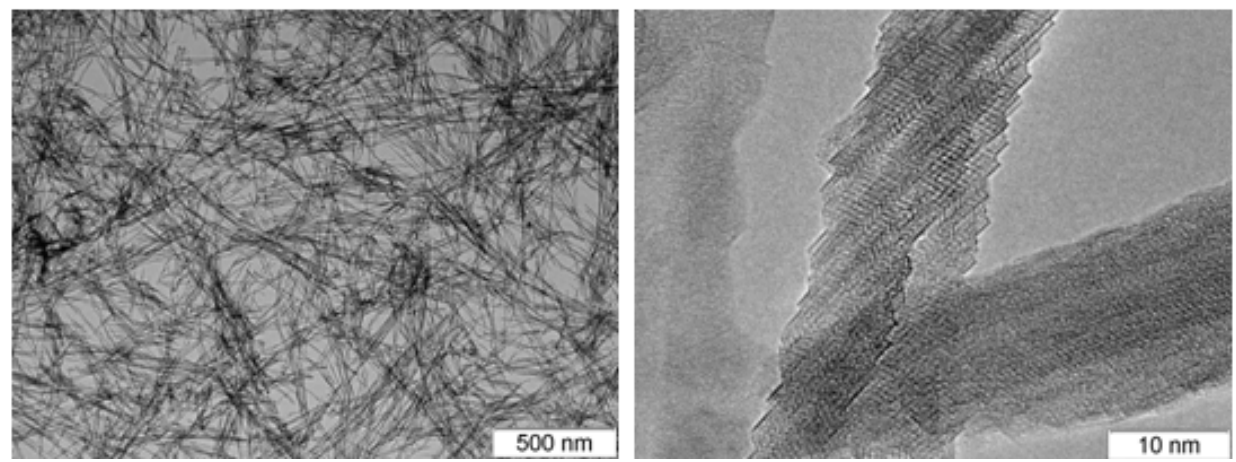

Рис. 2. Микрографии нановолокон оксида алюминия

Fig. 2. Electron micrographs of oxide nanofibers

Таблица 1. Параметры получения композита методом порошковой металлургии

Table 1. Parameters of composite manufacturing by powder metallurgy method

\begin{tabular}{|c|c|c|c|c|}
\hline $\begin{array}{c}\text { Тип упрочняющей } \\
\text { фазы }\end{array}$ & $\begin{array}{c}\text { Содержание } \\
\text { упрочняющей } \\
\text { фазы, \% масс. }\end{array}$ & $\begin{array}{c}\text { Параметры получения } \\
\text { смеси }\end{array}$ & $\begin{array}{c}\text { Параметры } \\
\text { компактирования }\end{array}$ & 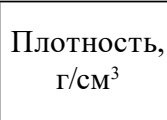 \\
\hline $\begin{array}{l}\text { Контроль без } \\
\text { добавок }\end{array}$ & 0 & \multirow{5}{*}{$\begin{array}{l}\text { Скорость вращения } \\
\text { барабана } 100 \text { об/мин. } \\
\text { Диаметр шаров } 10 \text { мм. } \\
\text { Время помола } 4 \text { ч }\end{array}$} & \multirow{3}{*}{$\begin{array}{l}\text { Нагрев } 77^{\circ} \mathrm{C} / \text { мин; } \\
\text { температура прессования } \\
580^{\circ} \mathrm{C} \text {; выдержка } 4 \text { мин; } \\
\text { давление } 40 \mathrm{MПа}\end{array}$} & 2,65 \\
\hline ОУНТ & 5 & & & 2,32 \\
\hline Нановолокна $\mathrm{Al}_{2} \mathrm{O}_{3}$ & 5 & & & 2,4 \\
\hline Нановолокна $\mathrm{Al}_{2} \mathrm{O}_{3}$ & 5 & & \multirow{2}{*}{$\begin{array}{l}\text { Нагрев } 77^{\circ} \mathrm{C} / \text { мин; } \\
\text { температура прессования } \\
620^{\circ} \mathrm{C} \text {; выдержка } 4 \text { мин; } \\
\text { давление } 40 \mathrm{MПа}\end{array}$} & 2,53 \\
\hline ОУНТ & 12 & & & 2,55 \\
\hline
\end{tabular}

цилиндрических образцах диаметром 18 мм. Снимки макроструктуры брикетов получали на оптическом микроскопе AltamiMet. Для исследования микроструктуры композита и смесей использовали сканирующий электронный микроскоп (СЭМ) MIRA3 TESCAN. Микрографии просвечивающей электронной микроскопии (ПЭМ) были получены с использованием микроскопа JEOLJEM-2010.

\section{Результаты и обсуждение}

Углеродные нанотрубки, а также оксидные нановолокна склонны к агломерации за счет сил Ван-дер-Ваальса. Поэтому для распределения их в металлическом порошке требуется приложить энергию, достаточную для разрушения агломератов. Наиболее простой и масштабируемый способ получения смесей наночастиц с порошком металла - это помол на мельницах. Для этого используют низко- и высокоэнергетические мельницы. Первые позволяют максимально сохранить структуру нанотрубок и нановолокон, нанося им минимальные повреждения в ходе помола, но требуют длительного времени обработки смеси для получения равномерного распределения наночастиц в порошке металла, хотя и это не обеспечивает полного разрушения

$$
-420-
$$


всех агломератов наночастиц в смеси. Помол на высокоэнергетических мельницах неизбежно приводит к возникновению повреждений в структуре УНТ и нановолокон и при длительном интенсивном воздействии может стать причиной их полного разрушения [11, 15]. Тем не менее смеси, полученные на таких мельницах, отличаются большей равномерностью и однородностью. Поэтому нельзя однозначно сказать, какой из методов помола будет наиболее эффективен в общем случае армирования композитов.

Из теории армирования известно, что модуль упругости определяется объемной долей и ориентацией армирующей фазы, ее модулем упругости, а также напряжением, передаваемым от матрицы на волокна. В связи с этим наличие армирующих добавок в виде УНТ и нановолокон $\mathrm{Al}_{2} \mathrm{O}_{3}$ должно оказать значительное влияние на упругие свойства композитов. Для получения лучшего эффекта от нанодобавок необходимо обеспечить хорошую адгезию между нановолокнами (или УНТ) и матрицей, кроме того, реализовать условия приготовления композита, обеспечивающие сохранность армирующей фазы. Высокоэнергетический помол может привести к уменьшению длины УНТ и нановолокон, их повреждению или даже к их полному разрушению, в результате значительно уменьшить или вовсе свести на нет ее влияние на модуль упругости композита. Поэтому с точки зрения получения максимального модуля упругости предпочтительнее использовать низкоэнергетический помол.

Микрографии СЭМ смесей, полученных с помощью низкоэнергетического помола на шаровой барабанной мельнице, приведены на рис. 3.

Видно, что при использовании низкоэнергетического помола сохраняются агломераты, их морфология для ОУНТ и оксидных нановолокон различна. Агломераты нанотрубок представляют собой клубки из переплетенных пучков УНТ, в то время как нановолокна склонны образовывать сростки из множества прямолинейных параллельно ориентированных волокон, напоминающих стержневидные частицы.

Снимки макроструктуры композитов показаны на рис. 4. На них отчетливо видны агломераты нановолокон и нанотрубок, имеющие размер до 100 нм для композитов с содержанием 5 \% масс. нанофазы. Для композита с содержанием 12 \% масс. УНТ размер скоплений нанофазы оценить невозможно, поскольку они представляют единую пористую сетку соединенных между собой агломератов.

Испытание композитов на изгиб показало, что добавки ОУНТ и оксидных нановолокон позволяют увеличить модуль упругости материала. Внесение 5 \% наноаддитива при формировании композита при $580{ }^{\circ} \mathrm{C}$ привело к росту модуля упругости на $30 \%$ (ОУНТ) и на $25 \%$ (нановолокна оксида алюминия). Повышение температуры формирования композита до $620^{\circ} \mathrm{C}$ позволило повысить модуль упругости на 87 \% при внесении 5 \% нановолокон оксида алюминия и на 189 \% при внесении $12 \%$ масс. ОУНТ (рис. 5 и табл. 2). Увеличение температуры электроискрового спекания привело к росту плотности материала как для алюминия с добавками нановолокон, так и для алюминия с добавками углеродных нанотрубок. Тем не менее прочность на изгиб для всех композитов оказалась меньше, чем для чистого алюминия без добавок, изготовленного тем же методом; это может быть связано с наличием агломератов, которые выступают в роли концентраторов напряжений. Относительная плотность полученных нами композитов была достаточно высокой (88-95 \%, табл. 2), однако нанодобавки, находящиеся в алюминии в виде агломератов, могут играть роль пор. Если в нашем случае это действительно

$$
-421-
$$



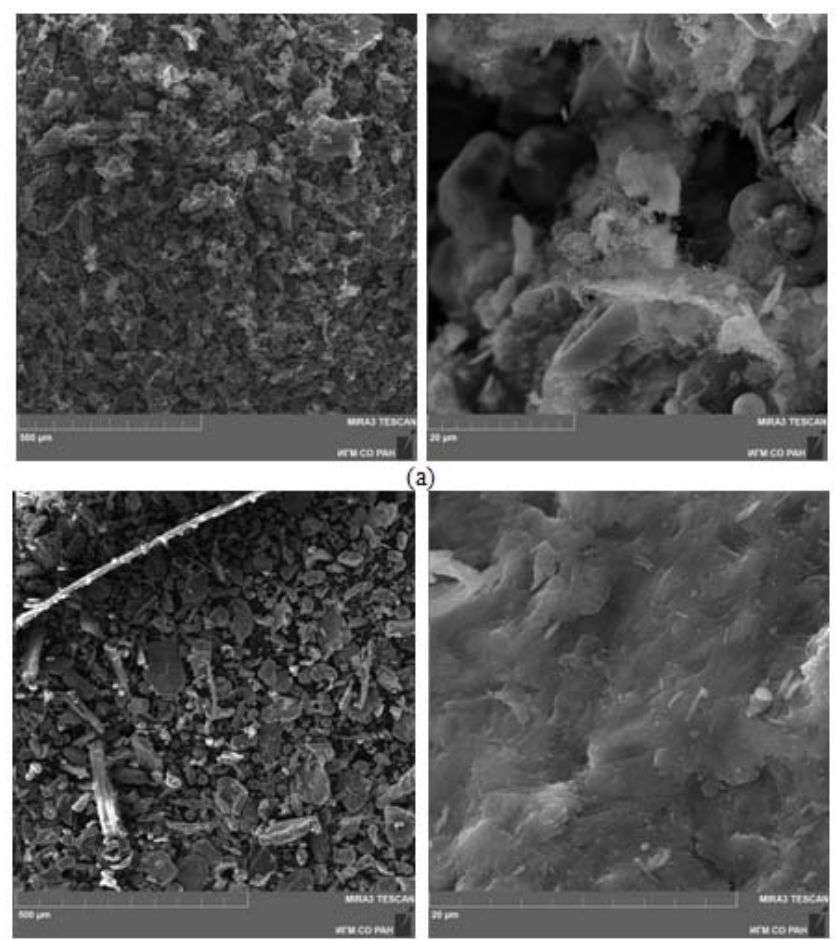

(ठ)
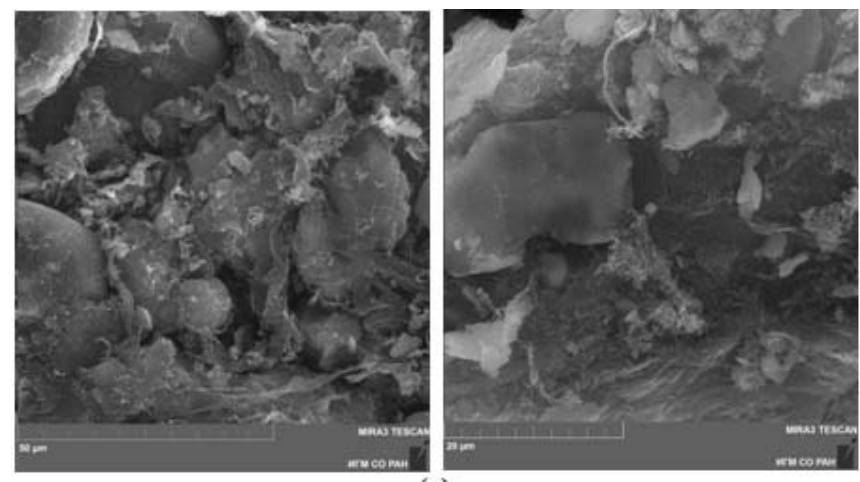

(B)

Рис. 3. Микрографии смесей: a - Al+5 \%SWCNT; б - Al+5 \%nano-Al2O3; в - Al+12 \%SWCNT

Fig. 3. Micro photos of powder mixtures: a $-\mathrm{Al}+5 \% \mathrm{SWCNT}$; $-\mathrm{Al}+5 \%$ nano-Al2O3; в $-\mathrm{Al}+12 \% \mathrm{SWCNT}$

так, тогда относительную плотность композитов следует рассчитывать не по теоретической плотности для выбранного содержания нанодобавки (как это сделано в табл. 2), но относительно плотности алюминия без добавок и соответственно этому определить пористость материалов. На рис. 6 показана зависимость прочности композитов на изгиб от пористости композитов, полученная с учетом вышеприведенного предположения. Видно, что имеется корреляция между пористостью и прочностью на изгиб, удовлетворительно совпадающая с теоретической зависимостью, описывающей влияние пористости на свойства материалов из металлических порошков, предложенной М.Ю. Бальшиным $[16,17]$. Следовательно, полученные нами низкие значения прочности на изгиб можно объяснить тем, что большая часть нанодобавок оказалась 

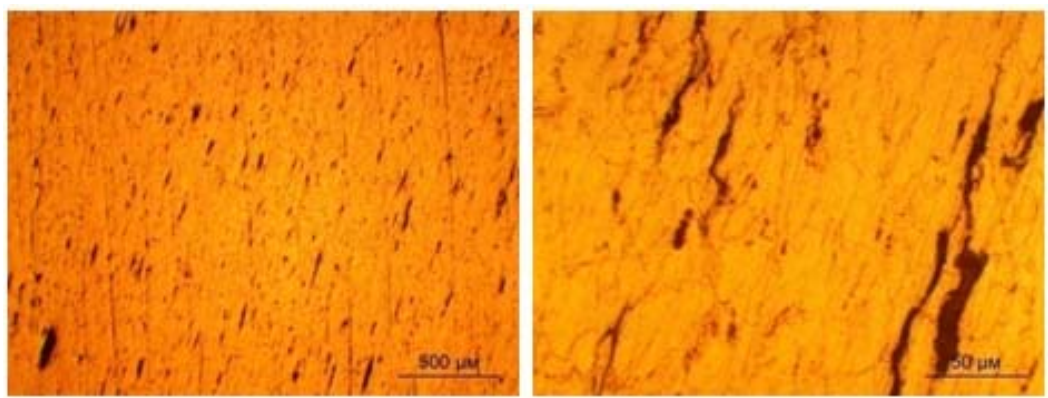

(a)
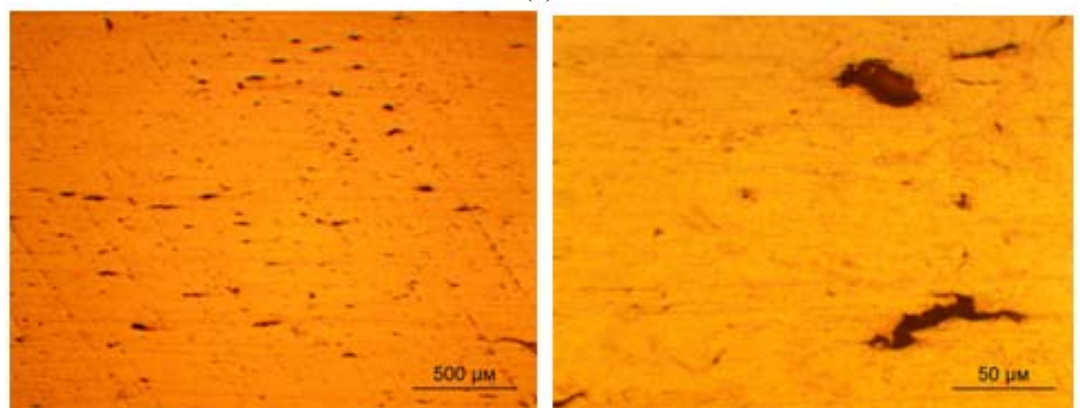

(б)

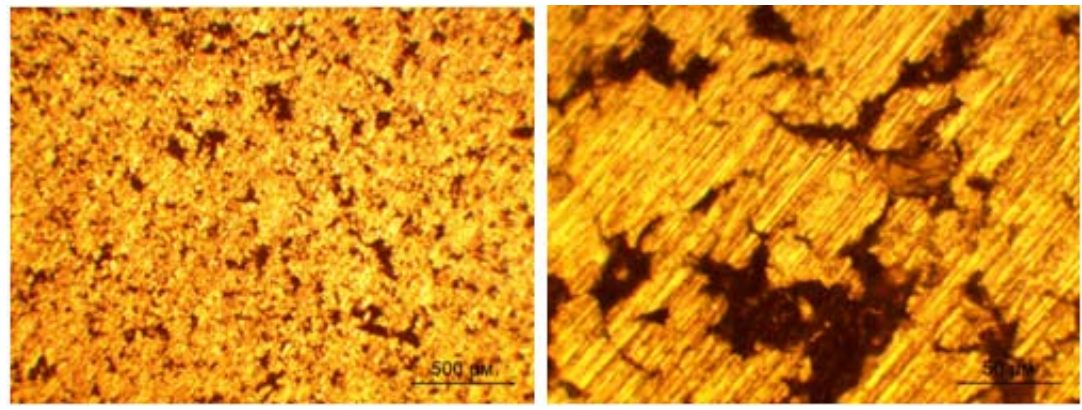

(B)

Рис. 4. Макроструктура композитов: а - композит $\mathrm{Al}+5$ \%УНТ; б - композит $\mathrm{Al}+5$ \%нановолокон $\mathrm{Al}_{2} \mathrm{O}_{3}$; в - композит $\mathrm{Al}+12 \%$ УНТ

Fig. 4. Composites microstructure: $\mathrm{a}-\mathrm{Al}+5 \% \mathrm{CNT} ; 6-\mathrm{Al}+5 \%$ oxide nanofibers; $\mathrm{B}-\mathrm{Al}+12 \% \mathrm{CNT}$

в виде агломератов, играющих роль пор и отрицательно влияющих на прочность композитов. Этот вывод согласуется с тем, что добавки ОУНТ и волокон не оказали заметного влияния на твердость алюминия.

Тот факт, что модуль упругости на изгиб увеличился при внесении нанодобавок, говорит о том, что часть УНТ и ОНВ все же была диспергирована в металлической матрице и выполнила роль армирующей фазы.

\section{Вывод}

Получены композиты на основе технического алюминия с добавками ОУНТ и оксидных нановолокон. Показано, что добавки 5-12 \%ОУНТ и 5 \%оксидных нановолокон позволяют увеличить значения модуля упругости на изгиб на 189 и 87 \% соответственно. 


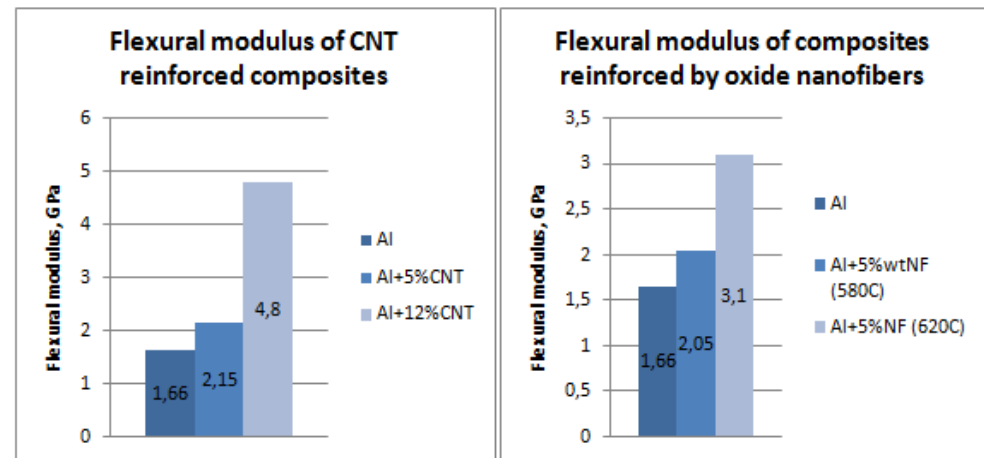

Рис. 5. Модуль упругости на изгиб композитов с ОУНТ и оксидными нановолокнами

Fig. 5. Flexural elastic modulus of CNT and oxide nanofibers reinforced composites

Таблица 2. Результаты испытания механических свойств композитов

Table 2. The results of mechanical testing of composites

\begin{tabular}{|c|c|c|c|c|c|c|}
\hline Тип смеси & 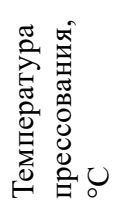 & 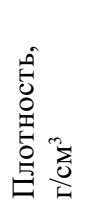 & 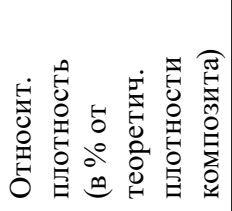 & 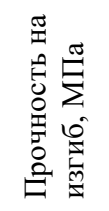 & 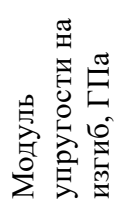 & 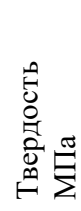 \\
\hline Контроль без добавок & \multirow{3}{*}{580} & 2,65 & 98,1 & 246,7 & 1,66 & 345,7 \\
\hline $\mathrm{Al}+5 \% \mathrm{YHT}$ & & 2,32 & 91,3 & 104,48 & 2,15 & 345,6 \\
\hline $\mathrm{Al}+5 \%$ нановолокна $\mathrm{Al}_{2} \mathrm{O}_{3}$ & & 2,4 & 88,2 & 129,3 & 2,05 & 367,2 \\
\hline $\mathrm{Al}+5$ \%нановолокна $\mathrm{Al}_{2} \mathrm{O}_{3}$ & \multirow{2}{*}{620} & 2,53 & 92,7 & 152,8 & 3,1 & 364,7 \\
\hline $\mathrm{Al}+12 \% \mathrm{УHT}$ & & 2,25 & 95,7 & 140 & 4,8 & 340,0 \\
\hline
\end{tabular}

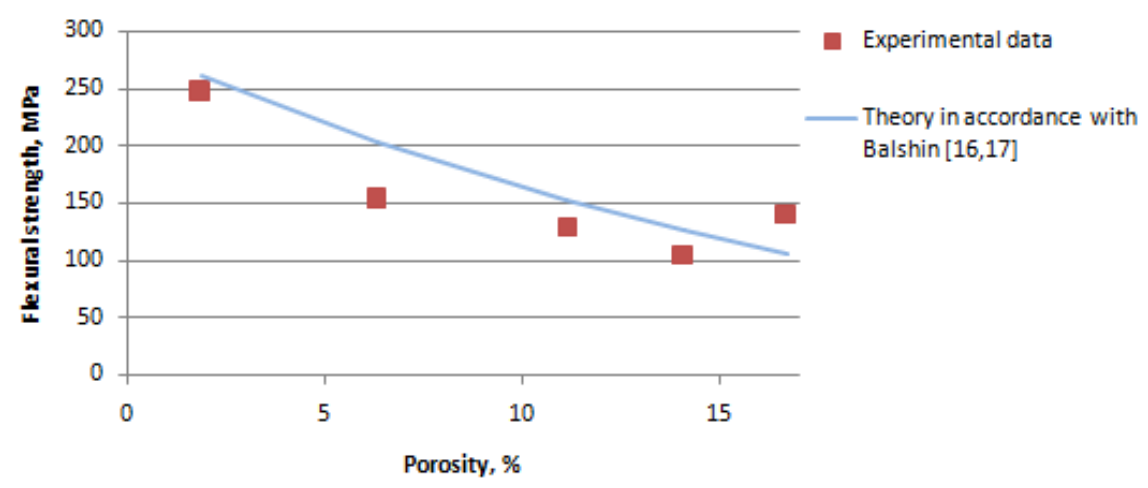

Рис. 6. Корреляция между прочностью на изгиб и пористостью композитов

Fig. 6. Correlation between flexural strength and porosity of composites 


\section{Список литературы}

[1] Abolfazl Azarniya, Mir Saman Safavi, Saeed Sovizi, Amir Azarniya, Biao Chen, Hamid Reza Madaah Hosseini, and Seeram Ramakrishna Metallurgical Challenges in Carbon NanotubeReinforced Metal Matrix Nanocomposites. Metals, 2017, 7(10), 1-44

[2] Jin-zhi Liao, Ming-Jen Tan, Idapalapati Sridhar Spark plasma sintered multi-wall carbon nanotube reinforced aluminum matrix composites. Materials \& Design, 2010, 31, 96-100

[3] Jinzhi Liao, Ming-Jen Tan Mixing of carbon nanotubes (CNTs) and aluminum powder for powder metallurgy use. Powder Technology, 2011, 208(1), 42-48

[4] Cavaliere P., Sadeghi B., and Shabani A. Carbon nanotube reinforced aluminum matrix composites produced by spark plasma sintering. J. Mater. Sci., 2017, 52(14), 8618-8629

[5] Biao Chen and Katsuyoshi Kondoh Sintering Behaviors of Carbon Nanotubes-Aluminum Composite Powders. Metals, 2016, 6(9), 213-218

[6] Baisong Guoa, Song Nia, Jianhong Yib, Rujuan Shena, Zhonghua Tanga, Yong Dua, Min Song. Microstructures and mechanical properties of carbon nanotubes reinforced pure aluminum composites synthesized by spark plasma sintering and hot rolling. Materials Science \& Engineering A, 2017, 698, 282-288

[7] Dong H. Nam, Seung I. Cha, Byung K. Lim, Hoon M. Park, Do S. Han, Soon H. Hong. Synergistic strengthening by load transfer mechanism and grain refinement of CNT/Al-Cu composites. Carbon, 2012, 50 (7), 2417-2423

[8] Hansang Kwon, Dae Hoon Park, Jean Franзois Silvain, Akira Kawasaki. Investigation of carbon nanotube reinforced aluminum matrix composite materials. Composites Science and Technology, 2010, 70(3), 546-550

[9] Bunakov N.A., Kozlov D.V., Golovanov V.N., Klimov E.S., Grebchuk E.E., Efimov M.S., Kostishko B.B. Fabrication of multi-walled carbon nanotubes-aluminum matrix composite by powder metallurgy technique. Results in Physics, 2016, 6, 231-232

[10] Singhal S.K., Pasricha Renu, Jangra Mamta, Chahal Rajiv, Teotia Satish, Mathur R.B. Carbon nanotubes: Amino functionalization and its application in the fabrication of Al-matrix composites. Powder Technology, 2012, 215-216, 254-263

[11] Yufeng Wu, Gap-Yong Kim, Alan M. Russell Effects of mechanical alloying on an Al6061CNT composite fabricated by semi-solid powder processing. Materials Science and Engineering A, 2012, 538, 164-172

[12] Hansang Kwon, Gil-Geun Lee, Sung-Gyoo Kim, Byung-Woo Lee, Won-Chan Seo and Marc Leparoux Mechanical properties of nanodiamond and multi-walled carbon nanotubes dualreinforced aluminum matrix composite materials. Materials Science and Engineering: A, 2015, 632, $72-77$

[13] Arun G. Kumar Investigation of flexural strength for carbon reinforced aluminum nano composite. International Journal of Mechanical Engineering and Technology (IJMET), 2017 8(12), 1083-1088

[14] Danilo Marini, Virgilio Genova, Francesco Marra, Giovanni Pulci, Marco Valente. Mechanical Behaviour with Temperatures of Aluminum Matrix Composites with CNTs. Chemical engineering transactions, 2017, 60, 25-30

$$
-425-
$$


[15] Dominique Poirier, Raynald Gauvin, Robin A.L. Drew Structural characterization of a mechanically milled carbon nanotube/aluminum mixture Composites Part A: Applied Science and Manufacturing, 2009, 40(9), 1482-1489

[16] Balshin M.Y. Relation of mechanical properties of powder metals and their porosity and the ultimate properties of porous metal-ceramic materials. Dokl Akad SSSR 1949, 67(5), 831-834

[17] Xudong Chen, Shengxing Wu, Jikai Zhou. Influence of porosity on compressive and tensile strength of cement mortar. Construction and Building Materials, 2013, 40, 869-874 